\title{
FINANCIAL COSTS OF PAEDIATRIC CANCER MANAGEMENT IN AFRICA: SYSTEMATIC REVIEW AND META-ANALYSIS
}

\author{
Criss Koba ${ }^{1}$, Désiré Kulimba ${ }^{2}$, Oscar Numbi ${ }^{3}$, Murielle Nkumuyaya ${ }^{3}$, Yves Chabu $^{4}$, \\ Prosper Kalenga ${ }^{3}$, and Benjamin Kabyla ${ }^{3}$ \\ ${ }^{1}$ University of Lubumbashi Faculty of Medicine \\ ${ }^{2}$ University of Kinshasa Faculty of Medicine \\ ${ }^{3}$ University of Lubumbashi \\ ${ }^{4}$ Missouri State University
}

February 1, 2021

\begin{abstract}
Background: Pediatric cancer is one of the leading causes of death and a matter of constant concern worldwide. The objective of this study was to estimate the financial cost of treating children suffering from cancer in Africa. Methods: We conducted a systematic review and meta-analysis of expert opinions with peer review by searching PubMed and other databases for World Health Organization data for the African region published in French and English between March 2000 and March 2020. The key search terms included 'cost', 'cancer' and 'child'; we selected articles that specifically addressed the financial costs of childhood cancer in African countries. Results: Of 79 articles found, 15 met the inclusion criteria; four of the articles came from Rwanda. Cancer care was a heavy financial burden in most of the countries studied, although costs varied from country to country; the average healthcare expenditure was US\$1017.39 \pm US $\$ 319.1$ per year. In countries without a health insurance system, the highest proportion of cancer care costs, $62.7 \%$, was indirect (e.g., travel costs to a different country for oncology care), whereas in countries with a cancer financing system, the direct cost of treatment was low, 37.3\%. Conclusion: The cost of treating childhood cancer is high in Africa in relation to the standard of living of individuals residing in this region. More studies on financing cancer care on this continent could improve treatment and patient management. Keywords: Childhood cancer, financial costs, Africa, systematic review, meta-analysis.
\end{abstract}

\section{Introduction}

Long considered the prerogative of high-income countries, cancer today no longer spares Africa, where the numbers of new cases and deaths are skyrocketing (a nearly 100\% increase is expected by 2030) [1]. The high costs of cancer treatment and lack of investment in health care are significant obstacles to public health on the African continent. African countries pledged through the Abuja declaration to allocate $15 \%$ of their gross domestic product to the healthcare sector; however, that objective has not been reached [2]. In most African countries, the patients bear a high percentage of healthcare expenses [3]; public health spending on the continent has primarily targeted infectious and parasitic diseases (AIDS, malaria, tuberculosis, etc.) and not cancer, and public aid from developed countries has similarly been targeted against epidemics, such as the Ebola virus and other crises, leaving the fight against cancer relegated to the background [4]. According to the Global Task Force on Expanded Access to Cancer Care and Control, only $5 \%$ of the world's cancer resources are spent in developing countries, and individual countries must draw up their own multiyear cancer plans adapted to their own socio-economic situations [5]. To our knowledge, no researcher has specifically estimated the costs of treating paediatric cancers in Africa. Thus, our objective with this work 
was to help with estimating the financial costs of paediatric cancers in Africa in a systematic review and meta-analysis.

\section{Methods}

The continent of Africa covers 20.3\% of the land area on Earth and 6\% of Earth's total surface. The continent has an area of $30,415,873 \mathrm{~km}^{2}$ including islands, and with the continent's population of over 1 billion inhabitants [6], Africans represent $16 \%$ of the world's population. For this study, we conducted systematic and advanced searches without language restriction using keywords on the costs of cancer in children in Africa in the following databases: Index Medicus African Health of the World Health Organisation (AFROLYB, AIM, Global Heath Library), PubMed, Cochrane Library, CISMeF and Google Scholar. In addition, we conducted a standard search using search bots. We searched article titles, summaries, reports, briefs, and any other electronic presentation for data on Africa with no restriction on format type or year. The keywords searched were as follows: 'cost of cancer', 'childhood cancer - socio-economic factors', 'cancer financing in Africa', 'prospective study' and 'African continent' using the logical separators AND (AND) and OR (OR).

The research items used were the following: $\{$ ('childhood cancers' [MeSH Terms] OR ('cost' [All Fields] AND 'cancer' [All Fields]) OR 'childhood cancer Africa' [All Fields] OR ('cost' [All Fields] AND 'cancer' [All Fields]) OR 'cost cancer' [All Fields]) AND ('diagnosis' [Subheading] OR 'diagnosis' [All Fields] OR 'cancer' [All Fields] OR 'cost in Africa' [MeSH Terms] OR ('mass tumoral' [All Fields] AND 'screening' [All Fields]) OR 'mass screening' [All Fields] OR 'cost' [All Fields] OR 'cancer in Africa' [All Fields]) AND ('cost' [MeSH Terms] OR 'cancer' [All Fields])\} AND (Meta-Analysis [ptyp] OR systematic [sb]).

The articles we selected supported assessing the cost of managing cancer in children aged 0 to 17 years in African countries. The inclusion criteria for the articles were (a) retrospective or prospective descriptive studies (b) conducted in any type of health structure in Africa between March 2000 and March 2020 in which the subjects were (c) children (d) with cancer irrespective of type who are younger than 17 years that (e) included descriptive information on paediatric cancer management; we did not include the different islands of the African continent in the study. We first selected articles on the basis of their titles, and then we searched the abstracts of those titles to screen for only meta-analyses or systematic reviews focusing on one or more aspects of the financial cost of childhood cancer. Finally, we performed a manual search of the sources in the reference lists of articles we had selected that our online searches had not detected.

The following information was collected for each study: study baseline, year of publication, number of cancers and cost data in US dollars. The results are presented according to the relevance of the research, the authors, the types of studies and the inclusion criteria. The costs were estimated in US dollars, and findings were analysed in Stata 11.0 (StataCorp LLC).

\section{Results}

Of the 79 referenced entries (47 on PubMed, 24 on Google Scholar and 8 in the Cochrane Library), 15 studies were selected; the latter group could also generally be found in the PubMed database (Figure 1).

\section{Figure 1: Flowchart of item selection}

The 15 articles were categorised by author, year, sample size, country and oncology unit (Table 1) and then sorted by number of publications on the costs of cancer care; there were four articles from Rwanda and one each from Algeria, Senegal, South Africa, Mali, Malawi, Kenya, Congo Brazza, Ghana and Nigeria.

Authors

Koba Mjumbe et al. (2020)

Renner et al. (2018)

Kabesha TA (2018)

Stulac et al. (2015)

Missaoui et al. (2011)

\section{Country}

Democratic Republic of Ghana [17]

Ivory Coast and DRC [

Rwanda [7-8]

Tunisia [12] 
Hesseling et al. (2009)

Malawi [9]

Akhivu (2009)

Abuidris et al. (2008)

Benin [11]

Wakabi (2008)

Soudan [10]

Merimikwa (2005)

Kenya and Uganda $[21]$

Doumbe et al. (2002)

Nigeria [13]

Freedman et al. (1976)

Cameroon [20]

South Africa [14]

${ }^{+}$Child subjects only. ${ }^{++}$Child and adult subjects. IC, indirect cost; DC, direct cost. $\quad+$ Child subjects only

Table 1: Summary of selected articles on the study of financial costs of paediatric cancer care in Africa

In most countries in Africa, paediatric cancer posed a significant economic burden on households. The disease cost varied from country to country with a cumulative average expenditure of US $\$ 1017.39 \pm$ US $\$ 319.1$ per year. Across countries, the majority of the cost for cancer management, $62.7 \%$, was indirect costs in countries that did not have a health insurance system; in countries with a cancer financing system, $37.3 \%$ was direct costs, which was considered low.

The most reported economic burden was the difficulty paying the bills, although the greatest burden was the toll the disease itself took on the children with cancer. Other economic burdens concerned the time lost leading to absenteeism, transportation to inaccessible hospitals, inadequate care practices, lack of qualified oncologists and high-quality treatment and delayed diagnoses.

\section{Discussion}

\subsection{Study characteristics}

Between March 2000 and March 2020, we selected 15 articles that met the inclusion criteria post reviewing the titles and abstracts of 79 indexed articles. Only 15 of the 54 countries in Africa were represented: Congo [6], Rwanda [7,8], Malawi [9], Sudan [10], Benin [11], Tunisia [12], Nigeria [13], South Africa [14], Zambia [15], Cote d'Ivoire [16], Ghana [17], Algeria [18], Tunisia [19], Cameroon [20] and Kenya [21]. It is possible that unpublished studies were conducted in this region during the study period, but we believe the results might be approximately the same. Most of the 79 studies we originally identified concerned the epidemiologic profiles, with only some discussion of cancer costs among women in medical oncology units. Fourteen articles focused on children, nine were studies on adults and the remainder included all patients admitted for cancer without gender specificity. The 15 published articles that we found in Africa in the above-mentioned time period by this systematic review were specific studies on the financial costs of cancer; the findings in seven of them revealed very high costs for cancer treatment across the continent.

Paediatric oncology units should include a well-established cancer registry and arrangements to reduce care costs. Unfortunately, the situation in Africa is still less than ideal. A number of countries in this region still lack dedicated cancer units, and patients who receive a cancer diagnosis face a sad fate including a significant economic burden. Many factors contribute to the lack of progress in oncology in Africa: limited governance and accountability, high political instability, natural disasters, underdeveloped infrastructures, and weaknesses in health systems [19].

\subsection{Financial costs of cancer care}

Several researchers in the studies we identified reported high costs for managing cancer in oncology units, the presence of which varied from country to country in Africa [20]. Costs were higher in countries that did not have a paediatric oncology department, and a significant financial burden of managing cancer was the indirect cost of travel by children and their caregivers to treatment units. In addition, during this study, we observed that the cost of care is on average US $\$ 109.5$ per pay, whereas the cost of the same care is US $\$ 1537.8$ in Angola [16]. 
The data from these studies show that in Africa, cancer care and diagnosis are expensive. The cost is the highest in the Democratic Republic of Congo (DRC) [22], although in three pilot treatment units (in the capital, Kinshasa; Haut-Katanga in Lubumbashi and Bukavu in the east), families can receive a loan of US $\$ 1419$ per year. In nearby Zambia and Rwanda, national subsidies for cancer patients significantly reduce the direct cost, to US $\$ 49$ and US $\$ 61$ per year, respectively for total costs of the care 49 USD and $\$ 61$ per year [22].

Generally, the cost of care depends on the country, its standard of living and its health policies. Countries with an oncology-centric system pay 10 times the average of countries without government subsidies [3], and consistent with those findings, we found that cancer care in the DRC cost 10 times more than it did in neighbouring countries - Rwanda, Zambia, and Congo Brazzaville. Financial inaccessibility is not usually a concern when household incomes are high. However, in the DRC, the gross domestic product per capita per year was estimated at US\$276 in 2013 [16], and in this study, the average monthly household income was US\$133.4, and the average annual household income was US $\$ 1921.40$; in the DRC, healthcare consumed $59.4 \%$ of the annual household income. Seven of 10 households in the DRC are poor [22], with $59.2 \%$ of the population living on less than US\$1 per day [23]. We also found that the heads of most households were self-employed $(43.1 \%)$.

We identified that cancer poses a significant financial burden on families of children with cancer in Africa; $72.2 \%$ of households spend more than $59.2 \%$ of their income on care, which explicitly explains the high proportion of unmet cancer care needs in Africa [3]. We note in particular, however, that the situation in the DRC is more than catastrophic, given that food alone accounts for $62.3 \%$ of household expenditure [19]. The costs of care are exorbitant and prohibitive for most households and paying for this care does not mean it is affordable for them. Families that pay to treat children with cancer are likely to face long-term economic and social repercussions related to debt repayment [11, 13], and the situation is the same for Malawi [7], Cameroon [17], Zimbabwe [23] and several other African countries where the costs of paediatric oncology care are beyond the reach of patients' families.

Faced with this situation, several states have introduced exemption and subsidy systems [19]. In Europe, for example, hospitalisation for cancer costs US $\$ 3,554.28$ per year for one patient, of which only $20 \%$ is paid by the patient [17]. In Mauritania, a flat rate system has been combined with user payment in public hospitals [8]. The oncology centre in Rwanda observed a significant increase in attendance when $90 \%$ of the cost of treatment was subsidised and a non-governmental organisation funded completely free treatment [24].

Through these different modes of financing health systems, different countries have succeeded in guaranteeing real access to paediatric oncology care [3]. Findings from a survey conducted in Haiti revealed that service use increased when care was free; free dispensaries of preventive care witnessed 2.87 times more patients than did dispensaries with fixed prices [25]. In the DRC, however, there is no health insurance system or user fee, although we note support from the GFAOP.5. Conclusion

We identified with this systematic review that the economic burden of paediatric cancer care is very high in Africa, although we found significant heterogeneity across the 15 studies, we identified from a systematic literature search and review. When households have to pay for cancer care themselves, the cost is catastrophic, if not outright prohibitive. Multiple factors explain these high costs, such as the lack of qualified personnel, inadequate quality care and lack of infrastructure, including the absence of cancer treatment centres in several African countries. We believe that our findings are limited by the small number of countries that were represented and of studies on the costs of cancer care in Africa. We suggest that increasing knowledge on these topics would support making informed policies for financing healthcare systems in African countries. In turn, better healthcare infrastructure will support better control of the growing pathology of paediatric cancer.

\section{State of current knowledge on the subject}

* Childhood cancer continues to cause high mortality that goes unnoticed in Africa 
* The cost of diagnosis and management is high and causes a significant economic burden

* In Africa, the lack of qualified personnel, lack of equipment in hospitals and socio-economic factors are obstacles to good cancer care

\section{Contribution of our study to knowledge}

* This review sheds light on the state of the costs of paediatric cancer care in hospitals in Africa

* Economic burdens are detailed and are for the most part common across African countries

* Finally, this study shows the need to encourage publications on the subject of paediatric cancer care in Africa to better understand the problem and reduce healthcare expenditures

\section{Conflicts of interest}

The authors declare no conflict of interest.

\section{Acknowledgements}

Our thanks go to all the authors of this article because they made a significant contribution to the design, implementation, analysis, and interpretation of the data. Thank you to ENAGO agency for the English language review and to the professors at the University of Lubumbashi Department of Public Health for their guidance during the conception of this work.

\section{Contributions from authors}

All authors have approved the final article

Criss Koba and Murielle Nkumuyaya: study design and planning

Benjamin Kabyla Ilunga, Desire Mashinda Kulimba, Oscar Luboya Numbi and Kalenga Mwenze: supervision

Criss Koba and Yves Chabu: statistical analysis and proofreading of the article.

Criss Koba: documentary research and formatting of the work

\section{Funding}

This research did not receive any specific grant from funding agencies in the public, commercial, or not-forprofit sectors.

\section{References}

1. Ferlay J, Shin HR, Bray F, Forman D, Mathers C, Parkin DM. GLOBOCAN 2008, cancer incidence and mortality worldwide. IArC CancerBase. 2010 May;10

2. Bona, K, Dussel, V, Orellana, L, Kang, T, Geyer, R, Feudtner, C, Wolfe, J. Economic impact of advanced pediatric cancer on families. J. Pain Symptom Manag. 2014; 47(3): 594-603.

3. Source Banque mondiale : Eliminer l'extreme pauvrete et promouvoir une prosperite partagee-2013

4. Criss KOBA M, Beatrice KOBA Bora, Jean Pierre Birangi et al. Psychosocial Lived Experience of Parents with Children Diagnosed with Cancer in Lubumbashi : Journal of Cancer Therapy. 2020.

5. Pison G - Sept milliards d'etres humains aujourd'hui, combien demain. Population et Societes 2011 ; 482, INED.

6. Alliance des Ligues francophones africaines et mediterraneennes contre le cancer. Les cancers en Afrique francophone. 2017. Paris. ALIAM.

7. Stulac S, Binagwaho A, Tapela NM, et al: Capacity building for oncology programmes in sub-Saharan Africa: The Rwanda experience. Lancet Oncol. 2015; 16: e405-e413.

8. Neal C, Rusangwa C, Borg R, et al. Cost of treating paediatric cancer at the Butaro cancer centre of excellence in Rwanda. J Glob Oncol. 2018; 4:1-7

9. Hesseling PB. Burkitt lymphoma treatment: The Malawi experience. African J Cancer. 2009; 1:72-79. 
10. Abuidris DO, Ahmed ME, Elgaili EM, Arora MS. Childhood cancer in Sudan 1999-2007. Trop Doct. 2008; 38: 208-210.

11. Akhiwu WO, Igbe AP, Aligbe JU, et al. Malignant childhood solid tumours in Benin City, Nigeria. West Afr J Med. 2009; 28: 222-226

12. Missaoui N, Khouzemi M, Landolsi H, et al. Childhood cancer frequency in the centre of Tunisia. Asian Pacific J Cancer Prev. 2011; 537-542.

13. Meremikwu MM, Ehiri JE, Nkanga DG, et al. Socioeconomic constraints to effective management of Burkitt's lymphoma in south-eastern Nigeria. Trop Med Int Health. 2005; 10: 92-98

14. Freedman J, Goldberg L. Incidence of retinoblastoma in the Bantou of South Africa. Br J Ophthal. 1976; 6: 655-656.

15. Israels $\mathrm{T}$, Paintsil V, Nyirenda $\mathrm{D}$, et al. Improved outcome at end of treatment in the collaborative Wilms tumour Africa project. Pediatr Blood Cancer. 2018; 65(5): e26945.

16. Kabesha TA, JJA Y, Budiongo AN, et al. Retinoblastoma in subSaharan Africa: Case studies of the Republic of Cote d'Ivoire and the Democratic Republic of the Congo. J Glob Oncol. 2018; 4: 1-8.

17. Renner L, Shah S, Bhakta N, et al. Evidence from Ghana indicates that childhood cancer treatment in sub-Saharan Africa is very cost effective: A report from the childhood cancer 2030 network. J Glob Oncol. 2018; 4: 1-9.

18. Russell HV, Panchal J, VonVille H, et al. Economic evaluation of paediatric cancer treatment: A systematic literature review. Paediatrics. 2013; 131: e273-287

19. Metzger M, Howard SC, Fu LC, et al. Outcome of childhood acute lymphoblastic leukaemia in resourcepoor countries. Lancet. 2003; 362: 706-708.

20. Doumbe P, Obama T, Mbakop A, et al. Lymphome de Burkitt a localisation maxillofaciale chez l'enfant au Cameroun: Aspects therapeutiques et evolutifs d'une serie de 28 cas a Yaounde Cameroun. Bull Liais Doc OCEAC. 2002; 35(2): 29-34

21. Wakabi W. Kenya and Uganda grapple with Burkitt lymphoma. Lancet Oncol. 2008; 9(4): 319.

22. Michel G, von der Weid NX, Zwahlen M, Redmond S, Strippoli MPF, Kuehni CE. Incidence of childhood cancer in Switzerland. The Swiss Childhood Cancer Registry. Pediatr Blood Cancer. 2008; 50: 46-51.

23. Kerr DJ, Midgley R. Can we treat cancer for a dollar a day? Guidelines for low-income countries. N Engl J Med. 2010; 369: 801-803.

24. Hesseling PB, Wessels G. Resources to manage childhood cancer in Africa: An analysis of scholarship applications for the 1994 SIOP Continental Africa Meeting. Med Pediatr Oncol. 1995; 25: 260.

25. John R, Ross H. The global economic cost of cancer. Report of Livestrong and American Cancer Society 00544. 2010. 